\title{
Cerebral Vasospasm - A serious obstacle in a successful aneurysm surgery
}

\author{
Florin Stefanescu, Stefanita Dima, Ram Vakilnejad, Mugurel Radoi \\ National Institute of Neurology and Neurovascular Diseases - Bucharest, \\ Neuropathological Department
}

\begin{abstract}
Background: Cerebral vasospasm that occurs after subarachnoid hemorrhage (SAH) can be an important cause of mortality and morbidity for patients successfully operated for a cerebral aneurysm.

Methods: Five cases of prompt diagnostic and surgical treatment of a cerebral aneurysm, with important SAH on cerebral computed tomography (CT) at onset, are presented. All patients were admitted in a poor neurological state and developed severe vasospasm. Both, the correct clipping of the aneurysm and the cerebral vasospasm were angiographic demonstrated in all cases. Two patients showed complete obliteration of one carotid artery.

Results: Postoperatory, four of the patients were treated with intrathecally administered nimodipine $(10 \mathrm{mg} / 50 \mathrm{ml})$. In three cases, the procedure caused the reverse of the vasospasm and clinical improvement of the patients. Their clinical outcomes were very good and were discharged with minimal neurological deficits. In one case, repeated intraarterial administration of nimodipine, showed no reduction of the vasospasm, and no improvement of patient's clinical status. The patient was conscious, but presented focal neurological deficits (hemiplegia and aphasia). One patient did not benefit from
\end{abstract}

this treatment and had a poor clinical outcome, remaining in a vegetative state.

Conclusions: Cerebral vasoconstriction after SAH could be an important obstacle in obtaining very good results in aneurysm surgery. Intra-arterial administration of nimodipine is an important and useful treatment, but good results in reversal severe cerebral vasospasm are not always mandatory.

Key words: cerebral aneurysms, cerebral vasospasm, clipping of the aneurysm, postoperative results.

\section{Introduction}

Cerebral vasospasm is a known source of considerable morbidity and even mortality following subarachnoid hemorrhage (SAH) $(17,20)$. It is a prolonged, sometimes severe, but ultimately reversible cerebral arterial narrowing that occurs days after subarachnoid space bleeding.

Angiographic vasospasm was first described by a neurosurgeon, Ecker, along with a radiologist, Riemenschneider, in Syracuse, New York, in 1951 (5). A number of studies described the direct relationship between the location and amount of subarachnoid blood seen on admission computed tomography (CT) and the risk and distribution of angiographic vasospasm (3, 21). In 1980, Fisher and co-workers provided a useful predictive grading scale 
for vasospasm based on the location and thickness of the clot (10).

First neurosurgical studies (12), which evaluated the impact of clinical and angiographic vasospasm over patients' outcome, estimated that roughly one half of patients with SAH developed angiographic vasospasm, one half of this group would become symptomatic and one half of these symptomatic patients would die of cerebral infarction. Modern perioperative care of SAH clearly improved this situation and the aggressive treatment of symptomatic vasospasm have reduced the combined risk of all morbidity and mortality due to vasospasm to between $10 \%$ and $15 \%$, in more recent SAH patient series $(2,8)$.

The aim of this study is to present five cases with severe angiographic and clinical vasospasm, in which, despite an early surgery that had provided a correct clipping of the aneurysms, and allowed an aggressive perioperative medical treatment of vasospasm, we faced important morbidity due to clinical vasospasm.

\section{Material and methods}

We reported the cases of five patients with important subarachnoid hemorrhage on CT scan at admission and who were diagnosed by four vessels digital subtraction angiography with cerebral aneurysms. In all cases, cerebral vasospasm implied the simultaneous presence of angiographic vasospasm and clinical vasospasm. In all cases, angiographic vasospasm was noted before surgery, at that time when the diagnostic cerebral arteriography was performed.

Admission Glasgow Coma Scale was between 6 and 10 points. As a rule for treatment of anterior circulation aneurysms in our neurosurgical department, we performed surgical clipping of the aneurysms as soon as possible after its diagnosis. In all five patients, we performed early aneurysm clipping, which afforded us the opportunity to mechanically reduce the subarachnoid clot burden and reduced the vasospasm risk. Interval between diagnostic and surgery ranged between 24 to 72 hours. Both, the correct clipping of the aneurysm and the postoperative presence of arterial vasospasm were angiographic demonstrated in all cases.

Nimodipine administration started at admission in continuous intravenous perfusion (at a speed varying between 8-12 $\mathrm{ml} / \mathrm{h}$ depending on blood pressure). In four cases, local intra-arterial nimodipine was infused during control arteriography. In one case, this procedure was repeated three times postoperatively.

\section{Illustrative case 1}

A 68 years female was admitted to our clinic, 8 days after the onset of symptoms, with the diagnostic of SAH. At admission she was in a poor neurological state, with a GCS of 8 points, somnolence, third left cranial nerve palsy, right hemiparesis and motor aphasia. Initial cerebral CT scan showed blood in the main subarachnoid cisterns and in most of the cortical sulci (Figure 1A). Cerebral angiography, performed in the next day after her admission, revealed a left posterior communicating artery aneurysm and an important cerebral vasospasm (Figure 1B). She was operated within 24 hours after admission, and the clipping of the left posterior communicating aneurysm was performed. In the second day after surgery, we performed control cerebral angiography (Figure 2B, C, D). It demonstrated the correct clipping of the aneurysm, but revealed a severe and diffuse cerebral 
vasospasm which involved anterior cerebral artery (ACA) andmiddle cerebral artery (ACM). In the same session, using the intra-arterial micro-catheter, we administrated locally nimodipine, in the both ACA and ACM arteries. Due to the severity of the vasospasm, the presence of symptomatic infarcts and the lack of the possibility to perform angioplasty, we repeated local administration of nimodipine by the mean of intra-arterial catheters two more times, in the 4th and, respectively, the 6th postoperative day. No signs of the resolving of the intensity of the vasospasm were demonstrated. Cerebral CT scans showed diffuse area of infraction in the ACA and ACM supplying territories on both sides (Figure 2A). Continuous intravenous perfusion of nimodipine was maintained 14 days after surgery. Despite a good evolution of her neurological status in the first postoperative week, meaning the improvement of the consciousness, right hemiparesis and aphasia, her neurological evolution became stationary in the second and third postoperative week and showed progressive worsening starting with the fourth week. After one month from surgery her GOS score was 3.

Her evolution complicated with bronchopneumonia and died 48 days after surgery.

Illustrative case 2

A 45 years old male was admitted to our clinic, 3 days after the onset of symptoms, presenting severe headache, neck stiffness, photophobia, confusion and a slight left hemiparesis. Initial cerebral CT scan (Figure 3A) showed subarachnoid hemorrhage and a thick clot in the anterior interhemispheric fissure (grade 3 on Fischer scale). Cerebral angiography, performed within 48 hours of his admission, revealed an anterior communicating artery aneurysm and vasospasm on the proximal portion of the left ACA (segment A1) and its distal branches (Figure 3B). He was operated after three days of his admission, and the clipping of the anterior communicating artery aneurysm was performed. In the third postoperative day, he showed increasing of his left hemiparesis and became somnolent.

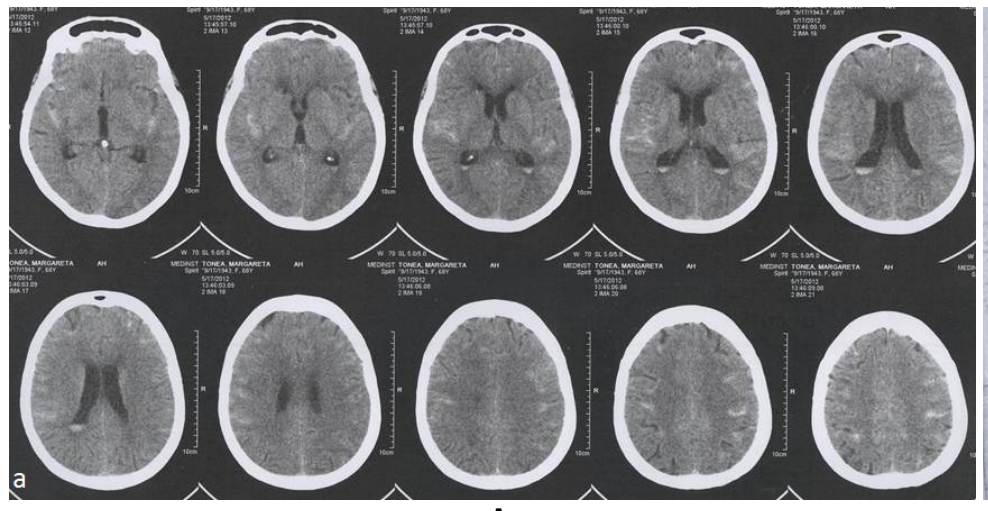

A

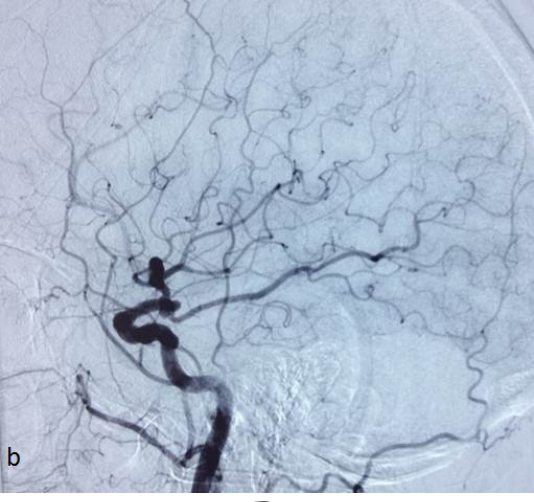

B

Figure 1. Preoperative images: (A) Native CT scan showing blood in the main subarachnoid cisterns and in most of the cortical sulci; Fischer scale-2, (B) four vessels cerebral angiography showed a left posterior communicating artery aneurysm and an important and diffuse cerebral vasospasm 


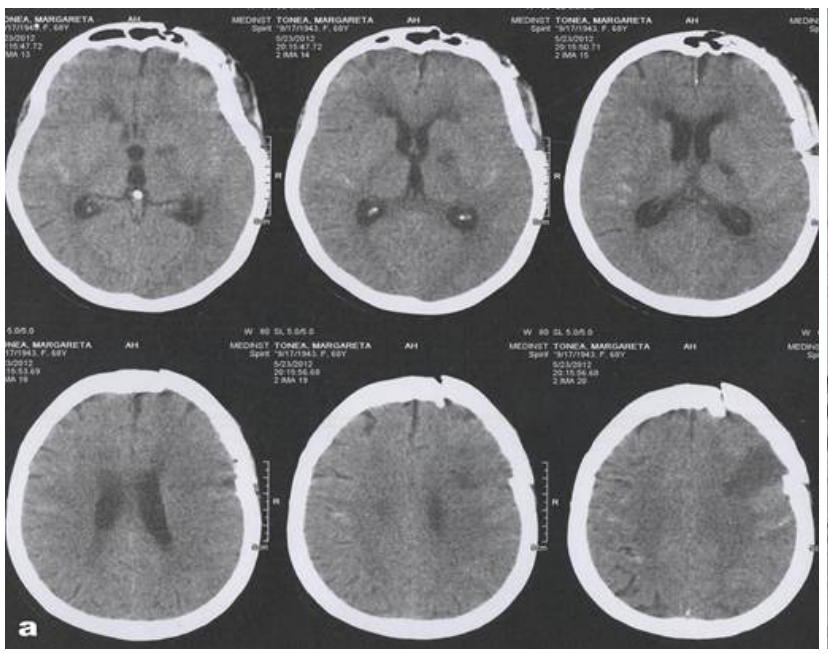

A

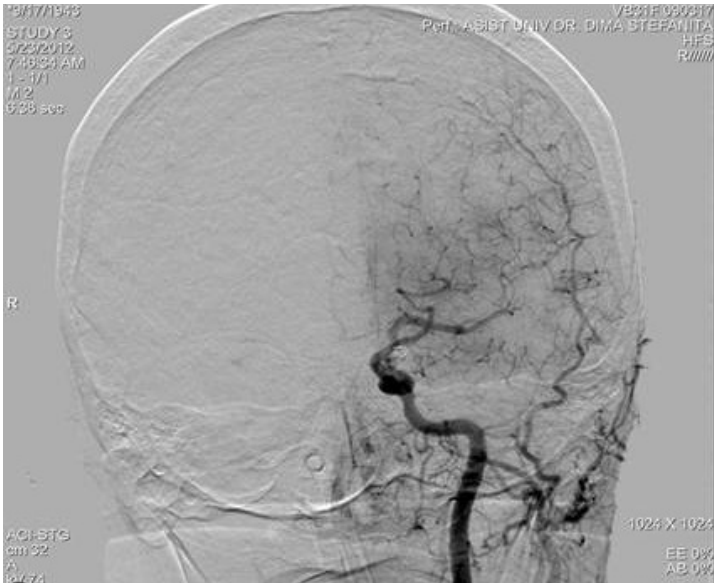

C

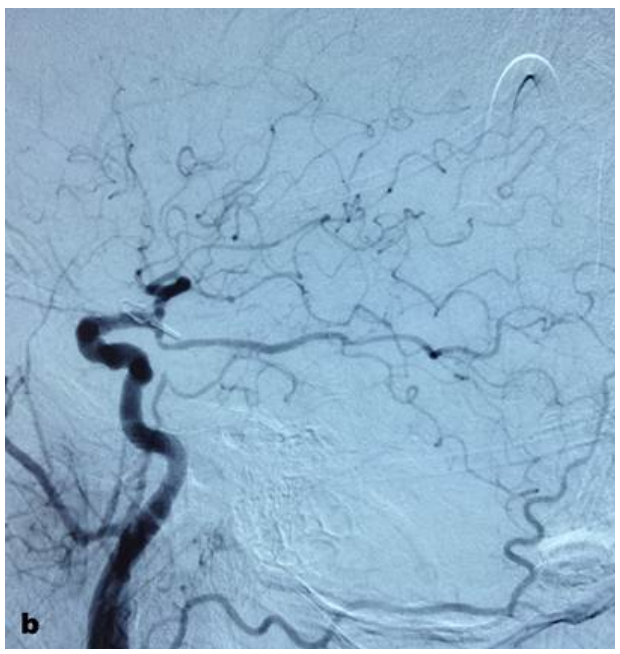

B

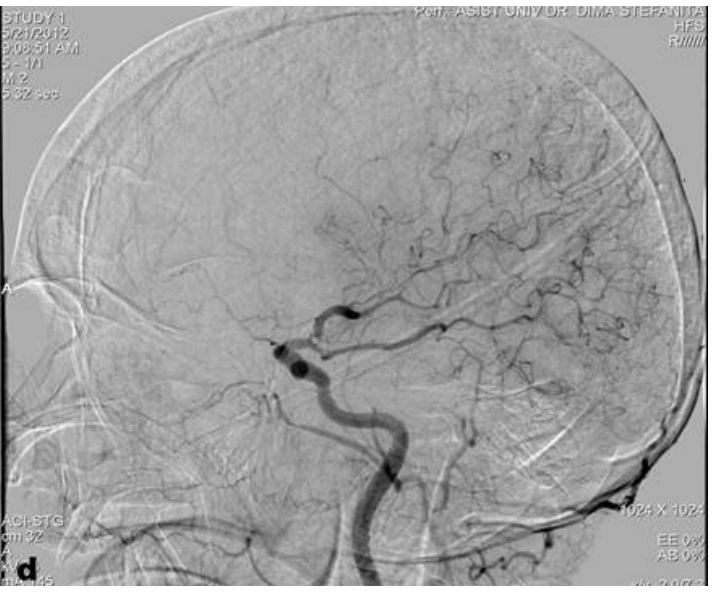

D

Figure 2. Postoperative images (48 hours after surgery): (A) - native CT scan showing ischemic hipodensities in the left ACA and ACM territories, (B, C, D) control cerebral angiography showed the correct clipping of the aneurysm and a severe and persistent vasospasm, which did not resolve after intra-arterial infusion of nimodipine

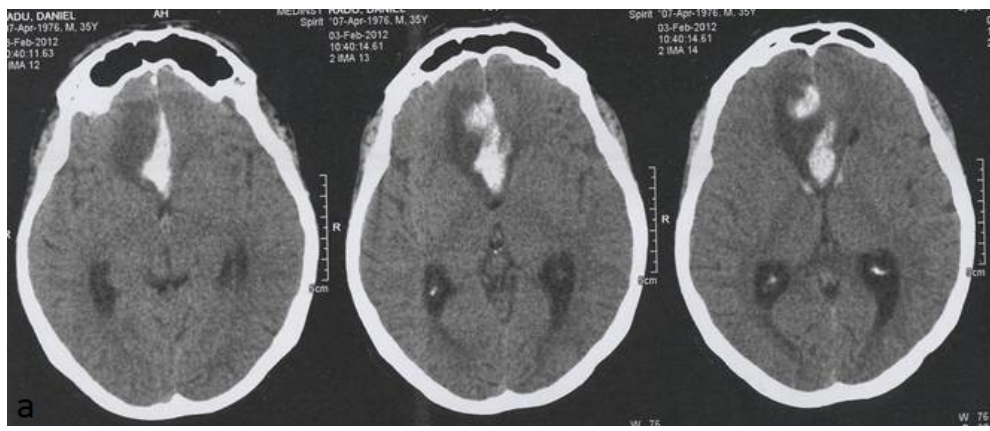

A

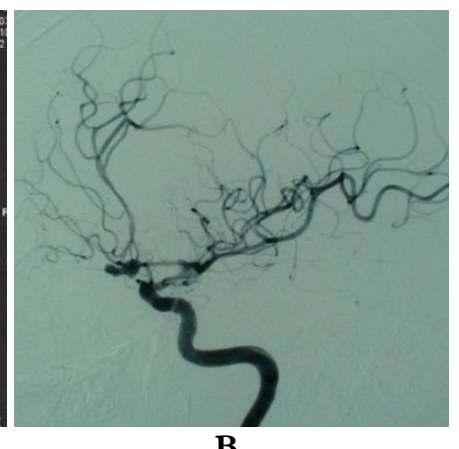

B

Figure 3. Preoperative images: (A) Native CT scan showing subarachnoid hemorrhage and a thick clot in the anterior interhemispheric fissure (grade 3 on Fischer scale), (B) four vessels cerebral angiography showed an anterior communicating artery aneurysm and vasospasm on the proximal portion of the left ACA (segment A1) and its distal branches 
Control angiography was performed four days after surgery, and demonstrated the correct clipping of the aneurysm (Figure 4B, C, D). Because of the increased vessels narrowing in the proximal and distal branches of the left ACA, compared with the diagnostic angiography, we locally injected nimodipine, using the intra-arterial micro-catheter, in order to reduce vasospasm in those arteries. Control CT scans showed the resolution of the initial frontal interhemispheric clot, and no other sign of focal ischemia (Figure 4A). Continuous intravenous perfusion of nimodipine was maintained 8 days after surgery, and it was continued orally. The medical treatment went successfully and the patient had no ischemic sequelae. He had a very good recovery and presented no permanent neurological deficits at 3 months follow-up (GOS - 15 points).
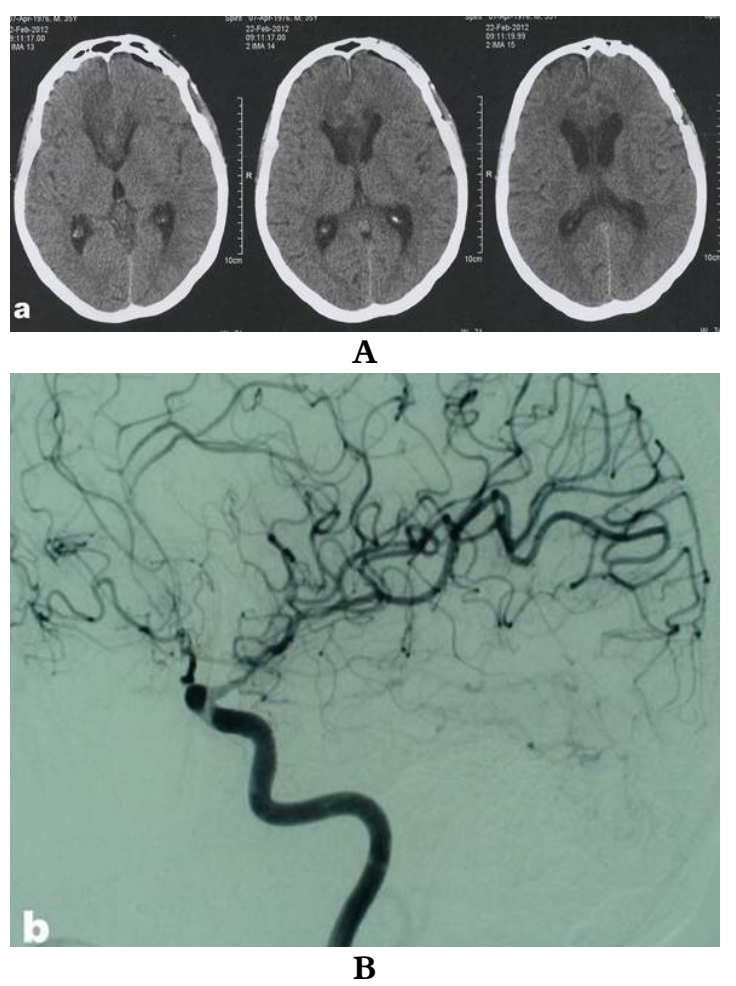

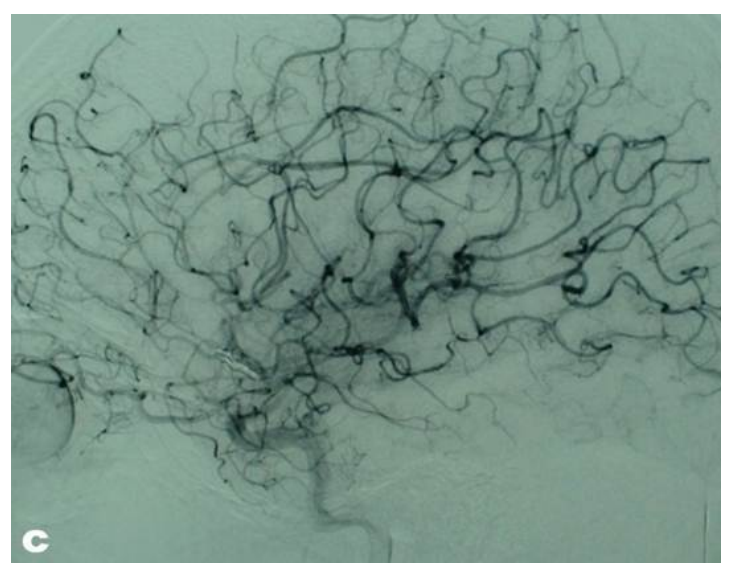

C

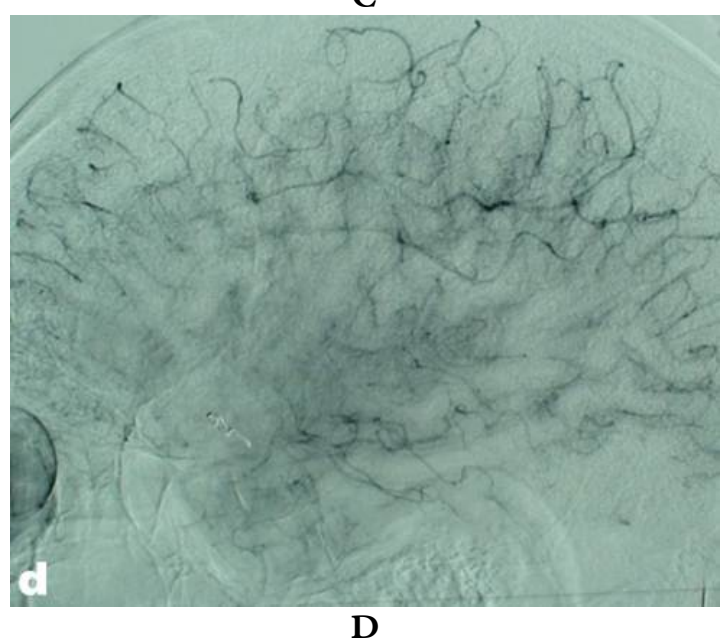

Figure 4. Postoperative images (4 days after surgery): (A) - native CT scan showing resolution of the initial frontal interhemispheric clot, and no other sign of focal ischemia, (B, C, D) control cerebral angiography showed the correct clipping of the aneurysm and moderate vasospasm in the proximal and distal branches of the left ACA

\section{Results}

Patient outcome was directly dependent on admission GCS, time interval between onset of symptoms and diagnostic/surgical treatment and intensity of vasospasm. It mainly affected the arterial branches of the anterior part of the circle of Willis. Unfortunately, two important means of reversing vasospasm were not used in our clinic: intra-arterial papaverine administration (lack of experience) and 
percutaneous transluminal balloon angioplasty (lack of materials). Only in one patient we noted the decreasing of vasospasm intensity at the control angiography. In two cases we encountered severe vasospasm, and, in the other three, the intensity was moderate. In one patient the aneurysm re-bleed before surgery, which delayed the clipping of aneurysm and led to development of hydrocephalus. The patients who presented a severe angiographic and clinical vasospasm, with signs of infarction on CT scan, had a poor outcome. One died of non-neurological complications (bronchopneumonia), and the other had permanent sequlae (GOS 3 ). In the other three patients, the medical treatment successfully reversed ischemia and vasospasm, and the outcome at 3 months after surgery was good, with minimal neurological deficits.

\section{Discussion}

A review of the literature found that the overall incidence of angiographic vasospasm after SAH was roughly $50 \%$, although the estimates ranged from $20 \%$ to nearly $100 \%$ (10). The variation appeared due to inconsistencies in the timing of cerebral angiography and definitions of vasospasm used (7). In a recent randomized trial, Findlay and co-workers, assessing the amount of subarachnoid clot on the admission CT scan, showed that almost $60 \%$ of patients with thick clots developed moderate to severe angiographic vasospasm in at least one major cerebral artery (9).

\section{TABLE 1}

Important clinical and imagistic parameters of a series of five patients with angiographic and symptomatic vasospasm

\begin{tabular}{|c|c|c|c|c|c|}
\hline & Case 1 & Case 2 & Case 3 & Case 4 & Case 5 \\
\hline Sex & $M$ & $\mathrm{~F}$ & $\mathrm{~F}$ & M & $\mathrm{M}$ \\
\hline Age & 45 & 68 & 58 & 41 & 51 \\
\hline Admission GCS & 10 & 8 & 8 & 6 & 10 \\
\hline Fischer scale & 3 & 2 & 4 & 4 & 2 \\
\hline Hunt $\alpha$ Hess & 2 & 3 & 3 & 4 & 2 \\
\hline $\begin{array}{l}\text { Interval between } \\
\text { onset/admission }\end{array}$ & 3 days & 8 days & 5 days & 4 days & 5 days \\
\hline $\begin{array}{l}\text { Interval between } \\
\text { diagnostic/surgery }\end{array}$ & $48 \mathrm{~h}$ & $24 \mathrm{~h}$ & $\begin{array}{c}\text { 72h (aneurysm } \\
\text { re-rupture) }\end{array}$ & $24 \mathrm{~h}$ & $24 \mathrm{~h}$ \\
\hline $\begin{array}{l}\text { Vasospasm before } \\
\text { surgery }\end{array}$ & yes & yes & yes & yes & yes \\
\hline $\begin{array}{l}\text { Vasospasm after } \\
\text { surgery }\end{array}$ & increased & increased & increased & decreased & increased \\
\hline $\begin{array}{l}\text { Other SAH related } \\
\text { complications }\end{array}$ & none & hydrocephalus & $\begin{array}{c}\text { Re- } \\
\text { rupture/hydroce } \\
\text { phalus }\end{array}$ & none & none \\
\hline $\begin{array}{l}1 \text { months follow-up } \\
\text { (outcome) }\end{array}$ & $\begin{array}{c}\text { Good } \\
(\text { GOS- 5) } \\
\end{array}$ & Poor (GOS-3) & Poor (GOS-3) & $\begin{array}{c}\text { Good } \\
(\text { GOS-4) }\end{array}$ & $\begin{array}{c}\text { Good } \\
(\text { GOS-5) }\end{array}$ \\
\hline $\begin{array}{l}4 \text { months follow-up } \\
\text { (outcome) }\end{array}$ & $\begin{array}{c}\text { Good } \\
(\mathrm{GOS}-5)\end{array}$ & Death & No dates & $\begin{array}{c}\text { Good } \\
(\text { GOS-5) }\end{array}$ & $\begin{array}{c}\text { Good } \\
(\mathrm{GOS}-5)\end{array}$ \\
\hline
\end{tabular}


Related to this subject is the demonstration that reducing the subarachnoid clot amount by early surgery (within 48 hours of rupture) decreases the risk of severe angiographic vasospasm (9, 19). Delayed-onset cerebral ischemia and infarction account for 15 to $20 \%$ of all unfavorable outcomes (22).

Risk factors for symptomatic vasospasm are: thick subarachnoid clots on cerebral $\mathrm{CT}$, poor neurological condition on admission, age younger than 35 and older than 65, cigarette smoking, preexisting hypertension, incomplete circle of Willis (19).

The most important measure in preventing vasospastic ischemia was avoiding of post-SAH hypovolemia, hypotension and raised intracranial pressure. Because all our patients presented angiographic and clinical vasospasm, we increased fluid administration in order to maintained systemic blood pressure in a moderate hypertensive range (140 to 160 $\mathrm{mmHg}$ ). Deliberate hypervolemia has not been proven to reduce symptomatic ischemia and can precipitate cardiopulmonary decompensation in older patients (1). We did not use transcranial Doppler in monitoring blood velocities, as a test to demonstrate the presence of angiographic vasospasm.

Nimodipine prevents intracellular calcium increases by blocking dihydropyridine-sensitive (L-type) calcium channels and in a series of randomized controlled trials has had a modest but statistically significant beneficial impact on clinical outcome after aneurysmal SAH (13, 15). The largest and most compelling study was the British Aneurysm Nimodipine Trial (BRANT) (16), which encompassed 554 patients of all grades, who received treatment within 4 days of hemorrhage, consisting of either placebo or nimodipine $60 \mathrm{mg}$ every 4 hours for 21 days. Results were as follow: cerebral infarction occurred in $22 \%$ of nimodipine-treated patients versus $33 \%$ of those who received placebo, and poor outcomes (severe disability, vegetative state and death) were significantly reduced in the nimodipine group, $20 \%$ versus $33 \%$ for placebo (16).

In our series, nimodipine administration started at admission in continuous intravenous perfusion, at a speed varying from $8-12 \mathrm{ml} / \mathrm{h}$ depending on blood pressure, and lasted for more than one week after surgery (range between 8 and 14 days). In all cases, parenteral administration of nimodipine was followed by oral uptaking for more than 7 days. In four cases, local cerebral intra-arterial nimodipine was infused during control angiography, and in one patient, the procedure was repeated three times after surgery, only for the mean to overcome the vasospasm.

Numerous treatments for cerebral arterial vasospasm have been evaluated. It is worth to be noted that vasospasm in humans does not respond to the large variety of drugs that reverse experimental vasospasm in animal models (11). Some of the treatment options in post-SAH vasospasm can only:

(a) prevent, but not reduce vasospasm early surgery with removal of blood clots, avoidance of hypovolemia and anemia

(b) protect the brain from ischemic injuries - calcium channel blockers, Nmetil-D-aspartate (NMDA) receptor antagonists, free radical scavengers (e.g tirilazad mesylate, nicaraven)

(c) improve the rheologic properties of intravascular blood to enhance perfusion of ischemic zones (e.g plasma, albumin, low 
molecular weight dextran) (11)

The only vasospasm treatment options that have been proved by many studies, to reverses ischemia or vasospasm are presented in Table 2 (7).

TABLE 2

Management of vasospasm and cerebral ischemia after aneurysmal SAH

Strategies for vasospasm and/or cerebral ischemia reversal after aneurysmal subarachnoid hemorrhage

\begin{tabular}{|l|l|}
\hline $\begin{array}{l}\text { Reverses } \\
\text { ischemia }\end{array}$ & $\begin{array}{l}\text { 1. Hypervolemia, hemodilution and } \\
\text { hypertension }\end{array}$ \\
\hline $\begin{array}{l}\text { Reverses } \\
\text { vasospasm }\end{array}$ & $\begin{array}{l}\text { 1. Intra-arterial papaverine } \\
\text { administration } \\
\text { 2. Percutaneous transluminal balloon } \\
\text { angioplasty }\end{array}$ \\
\hline
\end{tabular}

The presence of angiographic vasospasm within 48 hours of aneurysm rupture, as it was in our cases (at admission and detected on diagnostic angiography), although difficult to assess with certainty without a previous arteriography, has been correlated with a higher risk for later symptomatic vasospasm and a poor outcome (18). Our available options, in treatment of angiographic and clinical vasospasm, were the following:

(a) early surgery

(b)direct pharmacological arterial dilatation using calcium channel blockers (Nimodipine); using intra-arterial microcatheters, it was injected locally at the site of vasospasm, during control angiography

(c) Indirect intra-arterial dilatation utilizing triple $\mathrm{H}$ therapy

(d) Removal of potential vasospasmogenic agents (removal of blood clot and cerebrospinal fluid drainage)

(e) Administration of plasma, dextran or albumin to enhance perfusion of the ischemic zones.
As we previously underlined, two very important vasospasm treatment options, angioplasty and direct intra-arterial administration of papaverine, which were proved by several studies $(6,14)$ in reversing vasospasm, were not use in our clinic.

\section{Conclusion}

Many treatment strategies for combated angiographic and clinical vasospasm after aneurysmal subarachnoid hemorrhage have been described. Vasospasm remains an important clinical problem, a leading cause of preventable death and disability after SAH, and one of the most important independent predictors of poor outcome when it occurs. Intra-arterial administration of nimodipine is an important and useful treatment, but good results in reversal severe cerebral vasospasm are not always mandatory. In the future it is anticipated that better vasospasm prevention will be possible, likely through combined treatments, because vasospastic process is very complex. Nowadays, rescue treatment with hypervolemia, hypertension, and angioplasty is proved to be effective in reversing ischemia and preventing vasospasm-related morbidity and mortality.

Corresponding author:

Mugurel Petrinel Radoi MD, PhD

National Institute of Neurology and

Neurovascular Diseases - Bucharest,

Neurosurgical Department,

Postal Adress: 10-12 Berceni Str., 041902

Bucharest, Romania

E-mail address:muguradoi@yahoo.com

Phone: 0040723527292 


\section{References}

1. Bailes JE, Spetzler JF, Hadley MN, Baldwin HZ (1990). Management and morbidity of poor-grade aneurysm patients. J Neurosurg 72:559-566.

2. Broderick JP, Brott TG, Duldner JE, Tomsick T, Leach A (1994). Initial and recurrent bleeding are the major causes of death following subarachnoid hemorrhage. Stroke 25: 1342-1347.

3. Davis JM, Davis KR, Crowell RM (1980). Subarachnoid hemorrhage secondary to ruptured intracranial aneurysm: Prognostic significance of cranial CT. AJNR Am J Neuroradiol 1:17-21.

4. Dorsch NWC, King MT (1994). A review of cerebral vasospasm in aneurysmal subarachnoid haemorrhage: I. Incidence and effects. J Clin Neuroscience 1:19-26.

5. Ecker A, Riemenschneider PA (1951). Arteriographic demonstration of spasm of the intracranial arteries: With special reference to saccular arterial aneurysm. J Neurosurg 8:660-667, 1951.

6. Eskridge JM, McAuliffe W, Song JK, Deliganis AV, Newell DW, Lewis DH, Mayberg MR, Winn HR (1998). Balloon angioplasty for the treatment of vasospasm: Results of first 50 cases. Neurosurgery 42:510-517.

7. Findley J.M. (2004). Cerebral Vasospasm. In H. Richard Winn (Eds). Youmans Neurological Surgery Fifth Ed. (pp. 1839-1867). Philadelphia, Pennsylvania: Saunders Elsevier. ISBN 0-7216-8291-x.

8.Findlay JM, Deagle JM (1998). Causes of morbidity and mortality following intracranial aneurysm rupture. Can J Neurol Sci 25:209-215.

9. Findlay JM, Kassell NF, Weir BKA, Disney LB, Grace MGA (1995). A randomized trial of intraoperative, intracisternal tissue plasminogen activator for the prevention of vasospasm. Neurosurgery 37:168-178.

10. Fischer CM, Kistler JP, Davis JM (1980). Relation of cerebral vasospasm to subarachnoid hemorrhage visualized by computerized tomographic scanning. Neurosurgery 6:1-9.

11. Greenberg MS (2006). Handbook of Neurosurgery, Sixth Ed. Lakeland, Florida. Thieme Medical Publishers New York, NY.
12. Heros RC, Zervas NT, Varsos V (1983). Cerebral vasospasm after subarachnoid hemorrhage: An update. Ann Neurol 14:599-608.

13. Mee E, Dorrance D, Lowe D, Neil-Dwyer G (1988). Controlled study of nimodipine in aneurysm patients treated early after subarachnoid hemorrhage. Neurosurgery 22:484-491.

14. Nakagomi T, Kassell NF, Hongo K, Sasaki $T$ (1990). Pharmacological reversibility of experimental cerebral vasospasm. Neurosurgery 27:582-586.

15. Philippon J, Grob R, Dagreou F, Guggiari M, Rivierez M, Viars P (1986). Prevention of vasospasm in subarachnoid hemorrhage: A controlled study with nimodipine. Acta Neurochir 82:110-114.

16. Pickard JD, Murray GD, Illingworth R, Shaw MD, Teasdale GM, Foy PM (1989). Effect of oral nimodipine on cerebral infarction and outcome after subarachnoid hemorrhage: British aneurysm nimodipine trial. BMJ 298:636-642.

17. Qureshi AI, Sung GY, Razumovsky AY, Lane K, Straw RN, Ulatowski JA (2000). Early identification of patients at risk for symptomatic vasospasm after aneurysmal subarachnoid hemorrhage. Crit Care Med 28:948-990.

18. Qureshi AI, Sung GY, Suri MAK, Straw RN, Guterman LR, Hopkins LN (1999). Prognostic value and determinants of ultra-early angiographic vasospasm after aneurysmal subarachnoid hemorrhage. Neurosurgery 44:967-974.

19. Rabb CH, Tang G, Chin LS, Giannotta SL (1994). A statistical analysis of factors related to symptomatic cerebral vasospasm. Acta Neurochir (Wien) 127:27-31. 20. Ropper AH, Zervas NT (1984). Outcome 1 year after SAH from cerebral aneurysm. Management morbidity, mortality and functional status in 112 consecutive good-risk patients. J Neurosurg 60:909915.

21. Sano H, Kanno T, Shinomya Y. (1982). Prospection of chronic vasospasm by CT findings. Acta Neurochir (Wien) 63:23-30.

22. Zambraski J.M., Hamilton M.G (2000). Cerebral Vasospasm. In Carter LP a Spetzler RF (Eds). Neurovascular Surgery (pp. 583-600). McGraw-Hill, Inc. 